\title{
HUBUNGAN ANTARA DERAJAT KEPARAHAN STROKE DENGAN KEJADIAN STROKE-ASSOCIATED PNEUMONIA
}

\author{
ASSOCIATION BETWEEN STROKE SEVERITY AND STROKE-ASSOCIATED PNEUMONIA \\ Rega Dwi Wandira, * Lisda Amalia, ** Iwan Fuadi***
}

\section{ABSTRACT}

Introduction: Stroke-associated pneumonia (SAP) occurs in 5-26\% and decreases the quality of life and clinical outcomes of stroke patients. One of the factors that affect the incidence of SAP is the stroke severity.

Aims: To determine the association between the stroke severity and the incidence of stroke-associated pneumonia in the neurological ward of Dr. Hasan Sadikin Hospital, Bandung.

Methods: This is an analytic retrospective (historical) cohort design study. The study population was stroke patients who were treated in the neurological ward of Dr. Hasan Sadikin Hospital, Bandung between 2014-2016. Exclusion criteria were patient with pneumonia other than SAP and using mechanical ventilation. Stroke severity was assessed using NIHSS (National Institute of Health Stroke Scale). Chi-square was used to determine inter-variable association.

Results: Among 81 subjects, 24 were assessed as SAP (29.6\%). The SAP prevalence were mostly male (58.3\%), age group between $65-74$ year old (41.7\%) with hypertension risk (87.5\%), stroke onset $<48$ hours, lesion location on left hemisphere, onset of $S A P \geq 48$ hours, and those with consciousness impairment. Those with high stroke severity tend to have higher risk of pneumonia 3.063 times compare to patients with low stroke severity.

Discussion: There was a significant association between the severity of stroke and the incidence of SAP in the neurological ward of Dr. Hasan Sadikin Hospital, Bandung.

Keywords: NIHSS, stroke-associated pneumonia, stroke severity

\section{ABSTRAK}

Pendahuluan: Stroke-associated pneumonia (SAP) cukup sering terjadi (5-26\%) pada pasien stroke, sehingga menurunkan angka kualitas hidup dan luaran klinis. Salah satu faktor yang memengaruhi kejadian SAP adalah derajat keparahan stroke.

Tujuan: Mengetahui hubungan antara derajat keparahan stroke dengan kejadian SAP di Ruang Rawat Neurologi RSUP Dr. Hasan Sadikin, Bandung.

Metode: Penelitian analitik dengan desain kohort retrospektif (historikal) terhadap pasien stroke iskemik yang di rawat di Ruang Rawat Neurologi RSUP Dr. Hasan Sadikin, Bandung pada tahun 2014-2016. Kriteria eksklusi adalah pasien dengan pneumonia selain SAP dan menggunakan alat ventilasi mekanik. Derajat keparahan stroke dinilai menggunakan skor NIHSS (National Institutes of Health Stroke Scale). Uji korelasi Chi-square digunakan untuk melihat hubungan antar-variabel.

Hasil: Didapatkan 81 subjek yang 24 orang di antaranya mengalami SAP (29,6\%). Prevalensi SAP tertinggi pada laki-laki (58,3\%) kelompok usia 65-74 tahun (41,7\%) dengan faktor risiko hipertensi $(87,5 \%)$, onset stroke $<48$ jam, lokasi lesi di hemisfer kiri, onset $\mathrm{SAP} \geq 48$ jam, serta pada subjek dengan penurunan kesadaran. Subjek dengan derajat keparahan stroke berat memiliki risiko terjadinya pneumonia 3,063 lebih tinggi dibandingkan dengan derajat keparahan ringan.

Diskusi: Terdapat hubungan yang bermakna antara derajat keparahan stroke dengan kejadian SAP di Ruang Rawat Neurologi RSUP Dr. Hasan Sadikin, Bandung.

Kata kunci: Derajat keparahan stroke, NIHSS, stroke-associated pneumonia

*Program Sarjana FK Universitas Padjajaran, Bandung; **Departemen Ilmu Penyakit Saraf FK Universitas Padjajaran, Bandung; ***Anestesiologi dan Terapi Intensif FK Universitas Padjajaran, Bandung. Korespondensi: regadwiwandira@gmail.com.

\section{PENDAHULUAN}

Stroke berdasarkan World Health Organization (WHO) didefinisikan sebagai perkembangan tanda klinis secara cepat dari gangguan fungsi otak, yang bertahan lebih dari 24 jam atau mengarah pada kematian, dengan tanpa ada alasan lain selain kelainan yang berasal dari pembuluh darah otak. ${ }^{1}$ Di Indonesia, berdasarkan riset yang dilakukan oleh Kementerian Kesehatan Republik Indonesia (Kemenkes RI), jumlah penderita stroke di Indonesia sebanyak 1.236.825 orang dan Provinsi Jawa Barat menjadi provinsi dengan jumlah penderita stroke terbanyak sebesar 238.001 orang. ${ }^{2}$ Sebuah penelitian yang dilakukan di RSUP Dr. Hasan Sadikin, Bandung tahun 2012 yang menunjukkan bahwa prevalensi stroke terbanyak adalah stroke iskemik $(74 \%){ }^{3}$ 
Komplikasi medis yang paling sering terjadi saat perawatan stroke adalah pneumonia atau disebut stroke-associated pneumonia (SAP), sebesar 5-26\%. ${ }^{4}$ SAP biasanya muncul dalam waktu 48 jam dan berkembang dalam satu minggu, ${ }^{5-6}$ serta lebih sering terjadi pada stroke iskemik. Hal ini meningkatkan risiko mortalitas (49\%) dan luaran fungsional yang buruk (92\%), serta berkontribusi sebanyak 10\% penyebab kematian akibat stroke dan memperpanjang waktu perawatan pasien di rumah sakit sebanyak dua kali lipat. ${ }^{4,6}$

Derajat keparahan stroke diukur menggunakan National Institutes of Health Stroke Scale (NIHSS) yang merupakan alat ukur kuantitatif untuk defisit neurologis akibat stroke. Skala ini meliputi pemeriksaan neurologis, seperti tingkat kesadaran, fungsi berbicara dan bahasa, fungsi penglihatan, pergerakan bola mata, simetrisitas wajah, kekuatan motorik, sensasi, dan kordinasi. Skor NIHSS yang tinggi terbukti sebagai faktor risiko untuk pneumonia pada pasien stroke akut. ${ }^{7-8}$

\section{METODE}

Penelitian analitik dengan desain kohort retrospektif (historikal) terhadap pasien stroke iskemik yang dirawat di Ruang Rawat Neurologi RSUP Dr. Hasan Sadikin, Bandung. Data diambil dari rekam medis pada periode Januari 2014 sampai Desember 2016. Kriteria inklusi adalah pasien stroke yang dibuktikan dengan CT scan kepala dan mengalami infeksi paru (pneumonia) selama perawatan akibat strokenya. Adapun kriteria eksklusi adalah jika pasien mengalami pneumonia sebelum dirawat di Ruang Rawat Neurologi RSUP Dr. Hasan Sadikin, Bandung dan menggunakan alat ventilasi mekanik.

Penelitian ini telah mendapatkan persetujuan etik dari Komite Etik Penelitian Kesehatan Fakultas Kedokteran Universitas Padjajaran, Bandung. Derajat keparahan stroke dinilai menggunakan skor NIHSS. Skor ini mengandung 11 item pemeriksaan dengan rentang nilai 0 (tanpa gejala) hingga 42 (gejala stroke paling berat). Subjek dikatakan mengalami derajat keparahan yang berat jika memiliki nilai $>15$. Untuk menganalisis hubungan derajat keparahan stroke dengan kejadian SAP digunakan uji statistik korelasi Chi-square. Signifikansi uji ditentukan berdasarkan nilai $\mathrm{p}<0,05$.

\section{HASIL}

Didapatkan 81 subjek yang 24 orang di antaranya mengalami SAP $(29,6 \%)$, seperti pada Tabel 1 . Prevalensi SAP tertinggi pada laki-laki $(58,3 \%)$ kelompok usia 55-74 tahun $(62,5 \%)$ dengan faktor risiko hipertensi $(87,5 \%)$.

Tabel 1 Karakteristik Subjek dengan SAP $(n=24)$

\begin{tabular}{lc}
\hline \multicolumn{1}{c}{ Variabel } & n (\%) \\
\hline Usia (tahun) & \\
- $15-34$ & $0(0)$ \\
- $35-54$ & $6(25)$ \\
- $55-74$ & $15(62,5)$ \\
- $>75$ & $3(12,5)$ \\
Jenis Kelamin & \\
- Laki-laki & $14(58,3)$ \\
- Perempuan & $10(41,7)$ \\
Faktor Risiko & \\
- Hipertensi & $21(87,5)$ \\
- Diabetes melitus & $5(20,8)$ \\
- Merokok & $6(25)$ \\
\hline
\end{tabular}

SAP: stroke-associated pneumonia.

Tabel 2 menunjukkan SAP lebih banyak terjadi pada stroke iskemik $(58,3 \%)$ dengan lesi di hemisfer kiri $(70,8 \%)$, dalam awitan $<48$ jam $(70,8 \%)$, dan awitan SAP saat $\geq 48$ jam $(70,8 \%)$.

Tabel 2. Karakteristik Tipe dan Awitan Stroke pada Subjek dengan SAP $(n=24)$

\begin{tabular}{lc}
\hline \multicolumn{1}{c}{ Variabel } & n (\%) \\
\hline Tipe Stroke & $14(58,3)$ \\
- Iskemik & $10(41,7)$ \\
- Perdarahan & \\
Onset Stroke & $17(70,8)$ \\
- $<48$ jam & $7(29,2)$ \\
$\bullet \geq 48$ jam & \\
Onset SAP & $7(29,2)$ \\
- $<48$ jam & $17(70,8)$ \\
- $\geq 48$ jam & \\
Lokasi Lesi & $17(70,8)$ \\
- Hemisfer kiri & $7(29,2)$ \\
- Hemisfer kanan & \\
\hline
\end{tabular}

SAP: stroke-associated pneumonia.

Pada Tabel 3 diketahui SAP lebih banyak terjadi pada pasien dengan tingkat kesadaran somnolen $(54,2 \%)$. Untuk defisit neurologis, hemiparesis 
merupakan defisit neurologis yang paling tinggi $(91,7 \%)$ disusul dengan disfagi $(87,5 \%)$. Berdasarkan Tabel 4, Pola penggunaan antibiotik yang diberikan pada penelitian ini adalah kombinasi Seftriakson dan levofloksasin (37,5\%). Pada penelitian ini, tidak didapatkan data karakteristik klinis gangguan kognitif dan jenis bakteri pada SAP dikarenakan data yang tidak tersedia.

Tabel 3. Karakteristik Klinis pada Subjek dengan SAP $(n=24)$

\begin{tabular}{lc}
\hline \multicolumn{1}{c}{ Variabel } & n (\%) \\
\hline Tingkat Kesadaran & \\
- Kompos mentis & $5(20,8)$ \\
- Somnolen & $13(54,2)$ \\
- Sopor & $6(25)$ \\
- Koma & $0(0)$ \\
Defisit Neurologis & \\
- Disfagi & $21(87,5)$ \\
- Disartria & $17(70,8)$ \\
- Hemiparesis & $22(91,7)$ \\
Antibiotik & \\
- Seftriakson + levofloksasin & $9(37,5)$ \\
- Cefotaksim + levofloksasin & $6(25)$ \\
- Seftazidim + levofloksasin & $3(12,5)$ \\
- Levofloksasin + metronidazol & $1(4,2)$ \\
- Lain-lain & $5(20,8)$ \\
\hline
\end{tabular}

SAP: stroke-associated pneumonia.

Terdapat hubungan antara derajat keparahan stroke dengan kejadian SAP (Tabel 5) yang bermakna $(\mathrm{p}=0,01 ; \mathrm{RR}=3,063 ; \mathrm{IK} 95 \%$ 1,487-6,307). Pasien dengan derajat keparahan stroke berat memiliki risiko terjadinya pneumonia 3,063 kali lebih tinggi dibandingkan dengan derajat keparahan stroke ringan.

Tabel 4. Distribusi Kejadian SAP berdasarkan Derajat Keparahan Stroke $(\mathrm{n}=\mathbf{8 1})$

\begin{tabular}{lcccc}
\hline $\begin{array}{c}\text { Derajat } \\
\text { Keparahan } \\
\text { Stroke }\end{array}$ & SAP & Tidak SAP & & R $\%)$ \\
\cline { 2 - 3 } & $\mathbf{n}(\%)$ & & $\mathbf{p}$ \\
\hline Berat & $16(50)$ & $16(50)$ & 3,063 & 0,001 \\
Tidak berat & $8(16,3)$ & $41(83,7)$ & & \\
\hline SAP: stroke-associated pneumonia; RR: & risk ratio; & NIHSS: \\
National Institutes of Health Stroke Scale. & &
\end{tabular}

\section{PEMBAHASAN}

Berdasarkan penelitian Finlayson dkk, prevalensi SAP adalah $5-26,9 \%,{ }^{9}$ hampir sama dengan penelitian ini $(29,6 \%)$. Demikian pula penelitian lain menyatakan bahwa SAP merupakan salah satu komplikasi yang sering terjadi pada pasien stroke yang dirawat di rumah sakit, hingga dapat meningkatkan angka kematian karena stroke. ${ }^{4}$

Penelitian ini mendapatkan bahwa SAP mayoritas terjadi pada subjek laki-laki berusia 5574 tahun, sesuai dengan Liu dkk. ${ }^{10}$ Usia tua dapat menjadi risiko untuk SAP karena pasien stroke berusia tua cenderung memiliki gangguan kognitif yang berpengaruh terhadap penurunan fungsi tubuh, sehingga membuat derajat keparahan yang lebih tinggi. ${ }^{11}$ Demikian pula American Heart Association menyatakan bahwa kasus stroke lebih banyak terjadi pada laki-laki, sehingga meningkatkan peluang terjadinya SAP pada laki-laki. ${ }^{12}$ Liu dkk menyatakan SAP lebih banyak pada pasien laki-laki yang berhubungan dengan hormon seks. ${ }^{10}$

Temuan lainnya yang secara konsisten dengan penelitian sebelumnya yaitu SAP pada penelitian ini terjadi pada stroke iskemik, onset stroke $<48 \mathrm{jam}$, di hemisfer kiri, dan onset pneumonia $>48 \mathrm{jam} .{ }^{4,6,9}$ Pada penelitian ini, SAP lebih sering terjadi pada stroke iskemik. Temuan ini sesuai dengan penelitian Wagner dkk, yang menyatakan SAP lebih sering terjadi. Hal lain yang dapat menyebabkan tingginya prevalensi SAP pada stroke iskemik dibanding stroke perdarahan adalah lebih banyak jumlah kasus stroke iskemik pada penelitian ini. Hal ini serupa dengan penelitian sebelumnya tahun yang menunjukkan bahwa prevalensi kasus stroke terbanyak di RSUP Dr. Hasan Sadikin, Bandung, adalah stroke iskemik sebanyak $74 \% .^{3-4}$

Karakteristik onsetstroke $<48$ jamberhubungan dengan derajat kaparahan stroke yang lebih tinggi dan dalam rentang waktu tersebut risiko terkena SAP meningkat. Di sisi lain, lokasi lesi di hemisfer kiri berhubungan dengan nilai NIHSS yang lebih tinggi, sehingga pasien memiliki derajat keparahan yang lebih berat. Adapun onset pneumonia di atas 48 jam menandakan lama perawatan pasien di rumah sakit, sehingga risiko untuk menderita hospital-acquired infection turut meningkat. ${ }^{13-15}$

Berdasarkan hasil penelitian ini, SAP cenderung lebih sering terjadi pada pasien stroke yang memiliki faktor risiko hipertensi. Hal ini karena 
hipertensi diketahui sebagai faktor risiko stroke yang paling sering ditemukan. ${ }^{16-17}$ Karakteristik lainnya yang menunjukkan risiko SAP terjadi pada pasien dengan penurunan kesadaran, disfagi, dan hemiparesis. Hasil ini sejalan dengan penelitian yang telah dilakukan sebelumnya. ${ }^{14,6}$ Penurunan kesadaran berpengaruh pada kejadian SAP karena akan membuat penurunan protektif refleks batuk, mengganggu fungsi sfingter bawah esofagus dan mengganggu koordinasi antara bernapas dan menelan sehingga memiliki efek yang sama dengan disfagi yaitu meningkatkan risiko terjadinya aspirasi. ${ }^{6,18}$

Berdasarkan Sellar dkk, semakin tinggi disabilitas pasien stroke semakin tinggi kecenderungan terjadi aspirasi. Pasien dengan hemiparesis cenderung imobilisasi sehingga memiliki akumulasi sputum yang lebih banyak dan meningkatkan peluang terjadinya infeksi. ${ }^{19-20}$ Berdasarkan penelitian, mobilisasi awal dan segera, bila tidak diketahui adanya kontraindikasi, dapat menurunkan SAP. Mobilisasi dini diketahui dapat menurunkan risiko aspirasi dan meningkatkan pembersihan sekresi saluran napas. ${ }^{6,21}$ Pada penelitian ini tidak didapatkan data mikrobiologi dikarenakan proses kultur bakteri yang tidak dilakukan dengan alasan membutuhkan waktu yang lama, sehingga terapi antibiotik diberikan secara empirik berdasarkan evidence based bahwa bakeri penyebab SAP lebih sering berjenis gram negatif. Data antibiotik yang diperoleh sesuai dengan penelitian sebelumnya yaitu menggunakan seftriakson dan levofloksasin., ${ }^{6,22}$

Pada penelitian ini distribusi pasien stroke yang terdiagnosis SAP cenderung memiliki skor NIHSS yang tinggi (skor NIHSS $>15 /$ derajat keparahan berat) yaitu sebesar $67 \%$. Berdasarkan hasil uji statistik kejadian SAP terhadap derajat keparahan stroke, diperoleh nilai p sebesar 0,001 ( $R R=3,063 \mathrm{IK}$ $95 \%$ 1,487-6,307) yang berarti terdapat hubungan antara derajat keparahan stroke dengan kejadian SAP. Kerusakan pada otak pasien stroke mengakibatkan terjadinya proses imunokompromais sehingga pasien menjadi rentan terhadap infeksi.

Selain itu, kerusakan otak ini juga membuat proteksi dari jalur napas menurun dan terjadi gangguan proses menelan. Ini semua meningkatkan proses terjadinya aspirasi. Derajat keparahan yang berat menunjukkan bahwa kerusakan yang terjadi pada otak berat. Oleh karena itu, semakin tinggi derajat keparahan stroke membuat risiko aspirasi semakin tinggi dan dapat meningkatkan kejadian SAP. Hal ini serupa dengan penelitian lain yang menyatakan bahwa skor NIHSS yang tinggi merupakan faktor risiko yang kuat terhadap kejadian SAP. ${ }^{5-7,18}$

Keterbatasan penelitian ini adalah data yang didapatkan merupakan data sekunder. Hal ini membuka peluang untuk penelitian lanjutan dengan menggunakan data primer.

\section{KESIMPULAN}

Sebanyak 29,6\% pasien stroke memiliki komplikasi SAP dan cenderung memiliki nilai skor NIHSS yang tinggi. Hal ini menunjukkan adanya hubungan yang bermakna antara derajat keparahan stroke dengan kejadian SAP di Ruang Rawat Neurologi RSUP Dr. Hasan Sadikin, Bandung.

\section{DAFTAR PUSTAKA}

1. Sacco RL, Kasner SE, Broderick JP, Caplan LR, Connors JJ, Culebras A, dkk. An updated definition of stroke for the 21st century: a statement for healthcare professionals from the American Heart Association/American Stroke Association. Stroke. 2013;44(7):2064-89.

2. Kemenkes RI. Info Datin: situasi kesehatan jantung. Pusat Data dan Informasi Kementerian Kesehatan RI; 2014. h. 1-8.

3. Kartika D. Gambaran faktor risiko penderita stroke di Rumah Sakit Hasan Sadikin Bandung Periode Januari-Desember 2011. Universitas Kristen Maranatha; 2012.

4. Wagner C, Marchina S, Deveau JA, Frayne C, Sulmonte K, Kumar S. Risk of stroke-associated pneumonia and oral hygiene. Cerebrovasc Dis. 2016;41(1-2):35-9.

5. Emsley A, Hedley C, Hopkins SJ. Post-stroke immunodepression and infection: an emerging concept. Infectious Disorders-Drug Targets (Formerly Curr Drug Targets-Infectious Disorders). 2010;10(2):91-7.

6. Hannawi Y, Hannawi B, Rao CP, Suarez JI, Bershad EM. Stroke-associated pneumonia: major advances and obstacles. Cerebrovasc Dis. 2013;35(5):430-43.

7. Almeida SR, Bahia MM, Lima FO, Paschoal IA, Cardoso TA, Li LM. Predictors of pneumonia in 
acute stroke in patients in an emergency unit. Arq Neuropsiquiatr. 2015;73(5):415-9.

8. Wartenberg KE, Stoll A, Funk A, Meyer A, Schmidt $\mathrm{JM}$, Berrouschot J. Infection after acute ischemic stroke: risk factors, biomarkers, and outcome. Stroke Res Treat. 2011;2011:830614.

9. Finlayson O, Kapral M, Hall R, Asllani E, Selchen D, Saposnik G, dkk. Risk factors, inpatient care, and outcomes of pneumonia after ischemic stroke. Neurol. 2011;77(14):1338-45.

10. Liu DD, Chu SF, Chen C, Yang PF, Chen NH, $\mathrm{He} \mathrm{X}$. Research progress in stroke-induced immunodepression syndrome (SIDS) and strokeassociated pneumonia (SAP). Neurochem Int. 2018;114:42-54.

11. Sirven JI, Malamut BL. Clinical neurology of the older adult. Wolters Kluwer Health: Lippincott Williams \& Wilkins; 2008.

12. Haast RA, Gustafson DR, Kiliaan AJ. Sex differences in stroke. J Cereb Blood Flow Metab. 2012;32(12):2100-7.

13. Hassan MP, Tuckman HH, Patrick R, Kountz D, Kohn J. Hospital length of stay and probability of acquiring infection. Int J Pharm Healthc. 2010;4(4):324-38.

14. Prayoga M, Fibriani AR, Lestari N. Perbedaan tingkat defisit neurologis pada stroke iskemik lesi hemisfer kiri dan kanan. Biomedika. 2017;8(2):48-53.

15. Wu O, Cloonan L, Mocking SJ, Bouts MJ, Copen WA, Cougo-Pinto PT, dkk. Role of acute lesion topography in initial ischemic stroke severity and long-term functional outcomes. Stroke. 2015;46(9):2438-44.
16. Muela HC, Costa-Hong VA, Yassuda MS, Moraes NC, Memoria CM, Machado MF, dkk. Hypertension severity is associated with impaired cognitive performance. J Am Heart Assoc. 2017;6(1):e004579.

17. O’Donnell MJ, Xavier D, Liu L, Zhang H, Chin SL, Rao-Melacini P, dkk. Risk factors for ischaemic and intracerebral haemorrhagic stroke in 22 countries (the Interstroke study): a case-control study. Lancet. 2010;376(9735):112-23.

18. Visagan R. Post-stroke pneumonia - a clinical review of emerging concepts. King's College London School of Medicine. 2011. h. 1-12.

19. Sellars C, Bowie L, Bagg J, Sweeney MP, Miller $\mathrm{H}$, Tilston J, dkk. Risk factors for chest infection in acute stroke: a prospective cohort study. Stroke. 2007;38(8):2284-91.

20. Wang KW, Chen HJ, Lu K, Liliang PC, Huang CK, Tang PL, dkk. Pneumonia in patients with severe head injury: incidence, risk factors, and outcomes. J Neurosurg. 2013;118(2):358-63.

21. Passaro L, Harbarth S, Landelle C. Prevention of hospital-acquired pneumonia in non-ventilated adult patients: a narrative review. Antimicrob Resist Infect Control. 2016;5(1):43.

22. Torres A, Ferrer M, Badia JR. Treatment guidelines and outcomes of hospital-acquired and ventilatorassociated pneumonia. Clin Infect Dis. 2010;51(Supl 1):S48-53. 